\title{
CHARACTERIZATION OF TWO CELLULOSIC WASTE MATERIALS (ORANGE AND ALMOND PEELS) AND THEIR USE FOR THE REMOVAL OF METHYLENE BLUE FROM AQUEOUS SOLUTIONS
}

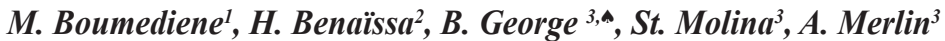

\begin{abstract}
The ability of orange peels (OP) and almond peels (AP) as adsorbents for the removal of a dyestuff, namely methylene blue (MB) from aqueous solutions has been studied. After their characterization by different techniques (elemental analysis, biochemical analysis, IR spectroscopy, thermogravimetric analysis, scanning electron microscopy, mercury porosimetry), adsorption kinetics of the dye have been investigated using common kinetic models cited in the literature: first order and pseudo-second order. The correlation coefficient has showed that the pseudo-second order kinetic equation best describes the adsorption kinetics for the tested materials. The experimental equilibrium data have been analyzed using linearized forms of Langmuir and Freundlich isotherms. The Langmuir isotherm was found to provide the best theoretical correlation of the experimental data whatever the biosorbents tested. Using the equilibrium coefficients obtained at different temperatures, various thermodynamic parameters such as $\Delta G^{\circ}, \Delta H^{\circ}, \Delta S^{\circ}$ have been calculated. The thermodynamics of $\mathrm{MB} / \mathrm{OP}$ and $\mathrm{MB} / \mathrm{AP}$ systems indicated spontaneous and endothermic process. It was concluded that an increase in temperature results in a higher MB loading per unit weight of OP or AP.
\end{abstract}

Keywords: adsorption, almond peels, isotherms, kinetics, modelling, orange peels, waste treatment.,

\section{INTRODUCTION}

Nowadays, water pollution control has become one of the major environmental problems. While coloured organic compounds generally impart a minor ratio of the whole organic load of wastewater, colour is one of the characteristics of an effluent that can be easily detected. Effluents from textile and dyestuff industries affect the nature of water, inhibit sunlight penetration and have a derogatory effect on photosynthesis. Moreover some dyes are mutagenic and/or carcinogenic. Thus, their removal is of major interest from scientific, environmental and health protection points of view. Decolourization of dye-containing effluent becoming an obligation both environmentally and for water re-use.

Some coloured organic compounds, among them methylene blue (MB), are not strongly hazardous but a prolonged exposure can cause vomiting, increase heart rate and be harmful to aquatic organisms (Martin et al. 1987). Apart from the fact that MB has wide applications (coating for paper stock, colouring paper, cotton or wool), this dyestuff is frequently chosen as a model compound in order to evaluate the removal capacity of substrates.

\footnotetext{
${ }^{1}$ Université de Tlemcen, Faculté de Technologie, Département d'Hydraulique, BP 230 Chetouane Tlemcen 13000. Algérie

${ }^{2}$ Université de Tlemcen, Faculté des Sciences, Département de Chimie, BP 119 Tlemcen 13000. Algérie

${ }^{3}$ Université de Lorraine, LERMAB, Faculté des Sciences et Technologies, Boulevard des Aiguillettes,

BP 7023954506 Vandoeuvre-les-Nancy cedex. France.

^Corresponding author: Beatrice.George@univ-lorraine.fr

Received : 22.05. 2013 Accepted : 20.03.2014
} 
Adsorption processes using suitable adsorbents are proved to be an effective and attractive technique for removal of dyes from wastewater (Robinson et al. 2001, Aksu 2005). Most systems use activated carbon as adsorbent to remove dyes (Wang et al. 2005), pesticides Daneshvar et al. 2007), phenols (Benturki et al. 2008) or other organic compounds Tsai et al. 2008) because of its excellent adsorption ability. Nevertheless, its widespread use is limited due to its cost and the problem of regeneration (Janoš et al. 2003). In recent years, it has led to the search of alternative low cost adsorbents including biosorbents, waste from agriculture or industry and natural materials. Previously, some teams of researchers have tested several low cost biomaterials for removal of MB in aqueous solution: sawdust (Otero et al. 2003), fallen phoenix trees leaves (Han et al. 2007), softstem bulrush (Li et al. 2008b), tea waste (Hameed 2009, Uddin et al. 2009), dead biomass (Nacèra and Aicha 2006), chaff (Han et al. 2006), Posidonia oceanica fibres (Ncibi et al. 2007).

The aim of the present work was to study the adsorption capacity of orange peels (OP) and almond peels (AP), for removal of MB from aqueous solutions. They are household wastes available in huge amount in Maghreb, hence cost effective adsorbents. The substrates were characterized using elemental analysis, biochemical analysis, Fourier transform infrared spectroscopy (FTIR), thermogravimetric analysis (TGA), scanning electron microscopy (SEM) and mercury porosimetry. Kinetics and adsorption isotherms were investigated, the system variables studied including contact time and initial MB concentration. Different adsorption models were used to fit the experimental data and to understand the biosorption mechanism. Thermodynamic studies were also carried out to estimate the thermodynamic parameters such as standard free energy $\left(\Delta G^{\circ}\right)$, enthalpy $\left(\Delta H^{\circ}\right)$ and entropy $\left(\Delta S^{\circ}\right)$ changes. These fundamental data will be useful for further developments in the treatment of practical waste or process effluents.

\section{MATERIALS AND METHODS}

\section{Adsorbents and chemicals}

OP and AP used as biosorbents are cheap and highly available lignocellulosic wastes in Algeria. OP (Tomson type) were collected in Mohammadia (Mascara -Algeria) while AP come from Bensekrane (Tlemcen - Algeria). The peels were naturally dried for 20 days (OP) or 30 days (AP) at temperatures between 303 and 308 K, crushed with a Moulinex Easy power R68 mill and sieved with an Automatic Sieve Shaker D403 device (Controlab) to keep only the size range from 1,25 to $2 \mathrm{~mm}$. The powdered materials have been thoroughly washed with distilled water to remove adhering dirt and then dried at $358 \pm 5 \mathrm{~K}$ in a stove for 24 hours.

MB (chemical formula: $\mathrm{C}_{16} \mathrm{H}_{18} \mathrm{CIN}_{3} \mathrm{~S} .3 \mathrm{H}_{2} \mathrm{O}$; molecular weight: $319,86 \mathrm{~g} / \mathrm{mol}$; analysis at wavelength 664 $\mathrm{nm}$; chemical structure given in Figure 1) was purchased from JANSSEN CHIMICA and used without further purification. It was chosen for this study because of its known strong adsorption onto solids.<smiles>CN(C)c1ccc2nc3ccc(N(C)C)cc3[s+]c2c1</smiles>

Figure 1. Chemical structure of methylene blue. 


\section{Characterization of adsorbents \\ Elemental analysis}

Ultimate analyzes were carried out in duplicate on an elementary analyzer THERMOFINNIGAN Flash EA 1112 fitted with an automatic sampler and a chromatographic column PORAPAK. The results i.e. Carbon, Hydrogen, Nitrogen or Oxygen \%wt were given at $\pm 0,2 \%$.

\section{Biochemical analysis}

This analysis aims to determine the amounts of the different constituents -lignin, holocellulose (cellulose + hemicelluloses) and extractives- contained in OP and AP.

The amounts of Klason lignin and holocellulose were determined according to protocols described in literature (Nguila Inari et al. 2007).

To determine extractives content, samples powders (size range between 1,25 and $2 \mathrm{~mm}$ ) obtained according to the protocol previously described in "adsorbents and chemicals" paragraph were treated in two steps with the accelerated extracting system ASE $200^{\circledR}$ of Dionex Company. In the first step, samples were put in contact with a solution of toluene/ethanol $95 \%(2 / 1 \mathrm{v} / \mathrm{v})$ at $373 \mathrm{~K}$ under 10,34 MPa pressure in 3 cycles for 1 hour. In the second one, powders, already extracted by toluene, were extracted by ethanol $95 \%$ under the same conditions as those used for the first extraction. The percentage of total extractives was deduced from the initial $\mathrm{mi}$ and final $\mathrm{mf}$ mass of dried sample (i.e. before and after extraction and after drying samples at 378 $\mathrm{K}$ for 48 hours) according the equation (1):

$$
\text { Extractives } \%=\frac{\boldsymbol{m}_{i}-\boldsymbol{m}_{f}}{\boldsymbol{m}_{i}} \times 100
$$

\section{Infrared spectroscopy}

Substrate $(1,5 \mathrm{mg})$ was crushed in a mortar with a pestle and mixed with potassium bromide $\mathrm{KBr}(99 \%)$ provided by ALDRICH TM $(30 \mathrm{mg})$. The powder obtained was then pelletized (pellet dimensions: diameter $\mathrm{x}$ thickness $=12 \mathrm{x} 1 \mathrm{~mm}$ ) under $700 \mathrm{kPa}$ pressure. The analysis was carried out using a spectro-photometer PERKIN ELMER Spectrum 2000 from 400 to $4000 \mathrm{~cm}^{-1}$.

\section{Thermogravimetric analysis}

Sample (about $80 \mathrm{mg}$ ) was introduced into the combustion boat of a thermobalance SETARAM Setsys TG 12 and heated from 293 to $973 \mathrm{~K}$ at $10 \mathrm{~K} \cdot \mathrm{min}^{-1}$ under an oxygen flow $\left(47 \mathrm{~cm}^{3} \cdot \mathrm{min}^{-1}\right)$. The heating rate of this order is generally considered able to ensure that no temperature gap exists between the sample and its surroundings (Bilbao et al. 1997). Ash content (inorganic fraction) and sample moisture were deduced from these experiments.

\section{Scanning electron microscopy}

SEM pictures were performed using a HITACHI S 4800 model microscope. Dry samples were coated with a thin layer of carbon before analysis under the microscope mark, in order to increase the sample conductivity. The resolution was $1 \mathrm{~nm}$ and the acceleration voltage was $15 \mathrm{kV}$.

\section{Mercury porosimetry}

To characterize the size distribution of particles, some measurements were carried out by mercury porosimeters PASCAL $140(\mathrm{Hg}$ pressures $<400 \mathrm{kPa})$ and PASCAL $240(100 \mathrm{kPa}<\mathrm{Hg}$ pressures $<400 \mathrm{MPa})$ from CE Instruments (England). 
The sample (300-350 mg) was introduced in the measuring cell and degassed under vacuum to reach a residual pressure of $0,01 \mathrm{kPa}$. Then the measuring cell was filled with mercury. The curve giving the intrusion volume of mercury as a function of applied pressure provides information about particles size, apparent density and specific area of sorbents assuming a cylindrical shape of pores.

\section{Adsorption procedure}

A stock solution of MB was prepared in distilled water and all working solutions were obtained by diluting the stock solution with distilled water to the desired concentration.

In each adsorption experiment, $1 \mathrm{dm}^{3}$ of dye solution of known concentration was added to $1 \mathrm{~g}$ of biosorbent in a $2 \mathrm{dm}^{3}$ round bottom flask at $298 \pm 1 \mathrm{~K}$ and the mixture was stirred on a magnetic shaker at $400 \mathrm{rpm}$. The supernatant solution was collected at predetermined time intervals and analyzed by a UV-visible spectrophotometer (UV-2550 SHIMADZU) at $\lambda_{\max } 664 \mathrm{~nm}$ to determine the residual dye concentration. The potential influence of dimerization of MB has been discussed and debated in literature (Patil et al. 2000, Ghanadzadeh et al. 2008, Tafulo et al. 2009). In our case, we have observed that the absorbance at $664 \mathrm{~nm}$ is consistent with the Beer-Lambert law. Consequently we have considered that the influence of dimers is not significant.

The MB uptake quantity was calculated by using the expression (2):

$$
q_{t}=\frac{V\left(C_{0}-C_{t}\right)}{1000 m}
$$

Where $\mathrm{q}_{\mathrm{t}}$ is the MB uptake quantity $\left(\mathrm{mg} \cdot \mathrm{g}^{-1}\right), \mathrm{V}$ the sample volume $\left(\mathrm{cm}^{3}\right), \mathrm{C}_{0}$ the initial MB concentration $\left(\mathrm{mg} \cdot \mathrm{dm}^{-3}\right), \mathrm{Ct}$ the residual MB concentration $\left(\mathrm{mg}^{-\mathrm{dm}^{-3}}\right)$ and $\mathrm{m}$ is the dry weight of the biosorbent $(\mathrm{g})$.

\section{RESULTS AND DISCUSSION}

\section{Characterization of adsorbents}

The results of elemental analysis are given in Table 1. Concerning OP, the proportions of $\mathrm{C}, \mathrm{N}$ and $\mathrm{O}$ obtained are in quite good agreement with the values presented by Lü et al. (2010) except for nitrogen (3,64\% in this contribution versus $0,84 \%$ for our samples) while some discrepancy can be observed with Zapata et al. (2009) results. Indeed these authors found (wt.\%): C, 49,59 and O, 39,7 i.e. an inverse proportion of \% C and \% O compared to our results (wt.\%): C, 39,8 and O, 46,9. Nevertheless such large differences could be explained on one hand by variability of substrates and on the other hand by the high inorganic content of our OP samples which was estimated around $5 \%$ from ATG. In the case of AP, the obtained results are similar to OP ones with a slightly higher carbon content.

Table 1. Elemental and biochemical analyses of orange and almond peels.

\begin{tabular}{|l|c|c|c|c|c|c|c|}
\hline & $\% \mathrm{C}$ & $\% \mathrm{H}$ & $\% \mathrm{~N}$ & $\% \mathrm{O}$ & $\begin{array}{c}\text { Extractives } \\
\%\end{array}$ & $\begin{array}{c}\text { Lignin } \\
\%\end{array}$ & $\begin{array}{c}\text { Holocellulose } \\
\%\end{array}$ \\
\hline OP & 39,8 & 5,9 & 0,8 & 46,9 & 15,0 & 32,0 & 50,0 \\
\hline AP & 45,5 & 5,8 & 0,8 & 45,7 & 5,3 & 40,0 & 51,0 \\
\hline
\end{tabular}


From biochemical analysis, we can notice that both substrates contain similar amounts of holocellulose but AP are richer in lignin than OP supporting the previous elemental analysis. Indeed higher the lignin content in the substrate and higher its carbon content compared to oxygen one. Besides, in OP, extractives amount is 3 times higher than in AP. Extractives are generally phenolic substances likely to interact with cationic dyes and we could expect enhanced MB adsorption capacity for OP. However the choice of these substrates appears interesting because they contain the same holocellulose content while lignin and extractives ones are quite different.

Figure 2 shows the FTIR spectra of dried OP and AP and Table 2 sums up the infrared bands in the 4000-400 $\mathrm{cm}^{-1}$ spectral region. The spectra present the characteristic bands that can be found on IR spectra of cellulose and lignin (Yang et al. 2007) and are in good agreement with literature (Zapata et al. 2009, Li et al. 2008a). The most intense band in the high energy region is due to a large amount of $\mathrm{OH}$ groups in the carbohydrates and in lignin. The intense band around $1065 \mathrm{~cm}^{-1}$ corresponds to the linkage C-O-H or C-O-R (alcohols or esters) while the band around $2925-2927 \mathrm{~cm}^{-1}$ can be assigned to $\mathrm{C}-\mathrm{H}$ stretching vibration together with bending vibrations around $1430-1440 \mathrm{~cm}^{-1}$ of aliphatic chains $\left(-\mathrm{CH}_{2}\right.$ and $\left.-\mathrm{CH}_{3}\right)$ or possibly methoxyl groups $\mathrm{O}-\mathrm{CH}_{3}$ on which lignocellulosic materials are based. Finally the band at $1618 \mathrm{~cm}^{-1}$ in AP can be attributed to aliphatic and/or unsaturated aromatic compounds while this band appears rather at $1635 \mathrm{~cm}^{-1}$ in OP. This band could also be related to $\mathrm{O}-\mathrm{H}$ stretching in adsorbed water.

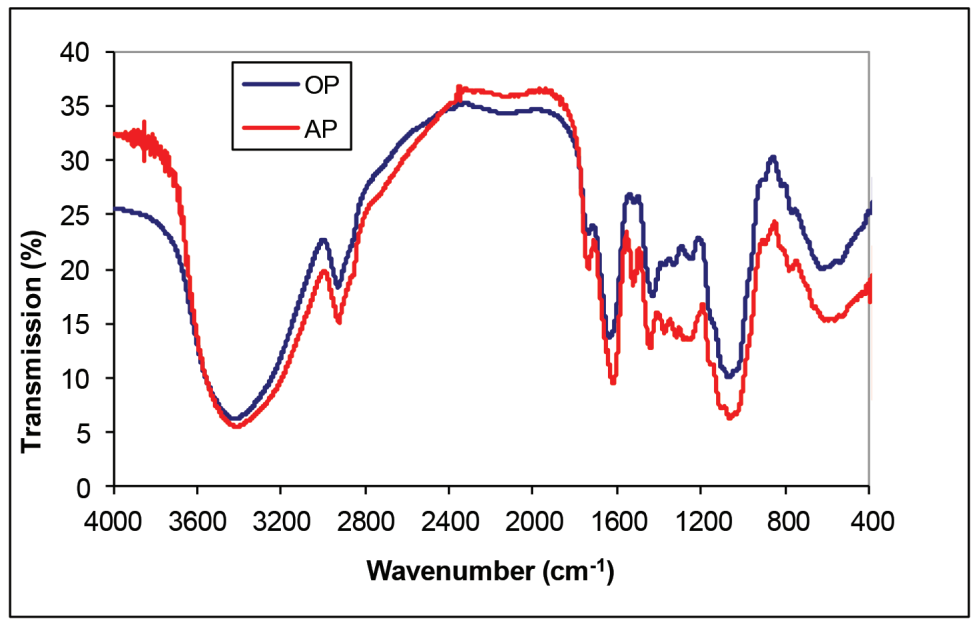

Figure 2. IR spectra of OP and AP biosorbents.

Table 2. Infrared bands in the $4000-400 \mathrm{~cm}^{-1}$ spectral region for both biosorbents $\left(\mathrm{cm}^{-1}\right)$.

\begin{tabular}{|l|c|c|}
\hline Functional groups of biosorbents & Orange peels & Almond peels \\
\hline O-H stretching & 3421 & 3413 \\
$\mathrm{CH}_{2}$ vibration & 2927 & 2925 \\
$\mathrm{C}=\mathrm{C}$ stretching & 1635 & 1618 \\
C-H bending & 1430 & 1440 \\
C-O-C, C-O-R vibration & 1065 & 1060 \\
Also in the finger print zone & 625 & 594 \\
\hline
\end{tabular}


Natural fibres are a complex mix of organic materials and consequently thermal treatment produces a variety of chemical and physical changes. Fibres thermal stability can be studied using thermogravimetric analysis (TGA). Figure 3 shows the thermogravimetric analysis (TGA) and derivative thermogravimetric (DTG) curves of OP sample heated under flowing air up to a final temperature of $973 \mathrm{~K}$. Four weight loss steps can be identified in the TGA/DTG curves, and their assignments can be made on the basis of previous works (Soares et al. 1995, Font et al. 1991). The first step which is observed between 373 and $483 \mathrm{~K}$ and appears as a shoulder with maximum weight loss rate near $473 \mathrm{~K}$ can be attributed to moisture traces release. A second step occurs between 513 and $573 \mathrm{~K}$, with maximum weight loss rate at $538 \mathrm{~K}$. It is attributable to degradation of hemicelluloses and organic and/or aqueous extractives. The third step in the temperature range 573-653 K, with a maximum weight loss rate at $613 \mathrm{~K}$, would correspond to thermal degradation of cellulose. The last step overlaps with the two previous ones and its characteristic temperatures cannot be distinguished so clearly. This weight loss step, due to lignin degradation, appears between 653 and $753 \mathrm{~K}$ with maximal weight loss rate near $679 \mathrm{~K}$. After all, our results are in good agreement with those obtained by Suárez-García et al. (2002) on apple pulp and Chen et al. (2011) on Chinese forest peat.

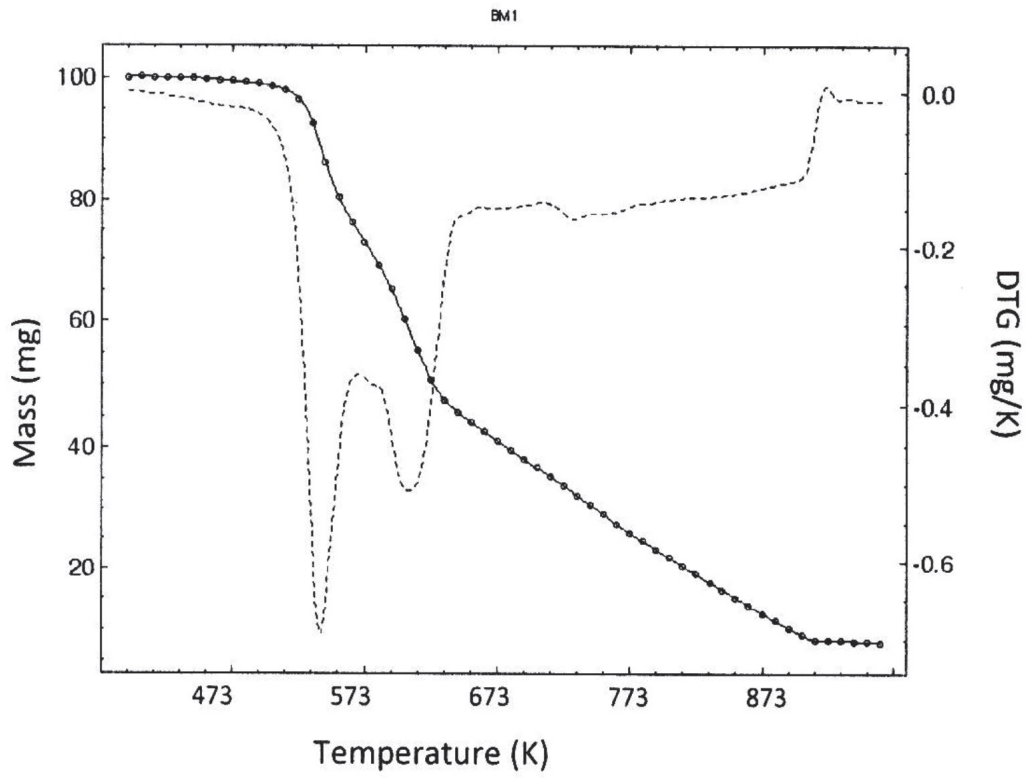

Figure 3. TGA and derivative TGA curves for OP. sample mass: $80 \mathrm{mg}$, heating rate : $10 \mathrm{~K} \cdot \mathrm{min}^{-1}$, Oxygen flow : $47 \mathrm{~cm}^{3} \cdot \mathrm{min}^{-1}$ (mass - $-_{-}^{-}$; DTG - - - ).

In the same way, Figure 4 presents the TGA and DTG curves obtained on AP. As previously, the first step between 373 and $483 \mathrm{~K}$ can be attributed to moisture traces release. In the second step, a maximum weight loss rate is observed around $533 \mathrm{~K}$, and can be attributable to degradation of hemicelluloses. We identified the third step through a maximum weight loss rate pointed at $613 \mathrm{~K}$, which corresponds to thermal degradation of cellulose. Above this temperature $(613 \mathrm{~K})$, the weight loss can be mainly assigned to lignin degradation that occurs in the range of 633 to $823 \mathrm{~K}$ on biomass (Suárez-García et al. 2002) but also to char and tar residues degradation. Up to about $573 \mathrm{~K}$, the DTG curves in air and nitrogen of various lignocellulosic materials are similar, showing that in this temperature range, the material does not undergo significant oxidation (Orfão et al. 1999), but only typical pyrolysis reactions, leading to the release of volatiles (Wongsiriamnuay and Tippayawong 2010). In the presence of oxygen, the formation of volatiles is promoted during thermal decomposition of lignin and $\mathrm{O} 2$ gasifies the residue formed in the meantime. The mass loss between 533 and $613 \mathrm{~K}$ can be ascribed to the combined effect of lignin pyrolysis and char oxidation. The differences observed between curves of both materials are thus directly related to the lignin amounts: $32 \%$ for OP versus $40 \%$ for AP. 


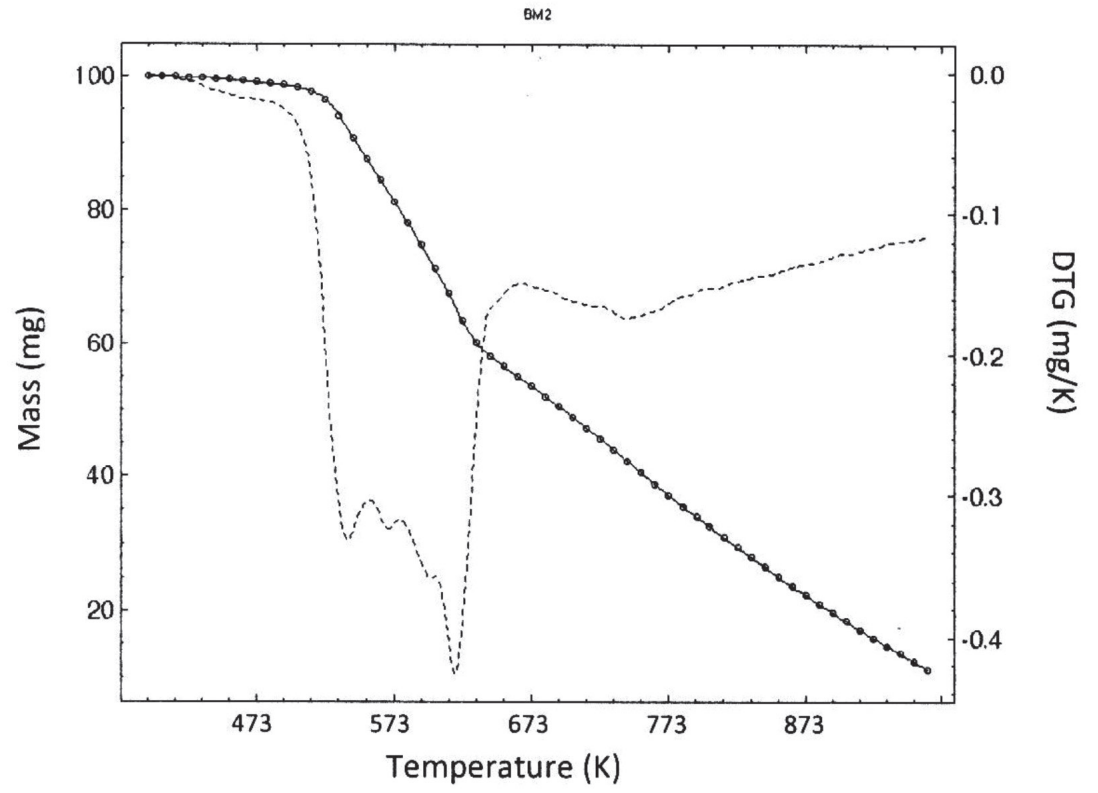

Figure 4. TGA and derivative TGA curves for AP. sample mass: $80 \mathrm{mg}$, heating rate: $10 \mathrm{~K} \cdot \mathrm{min}^{-1}$, Oxygen flow: $47 \mathrm{~cm}^{3} \cdot \mathrm{min}^{-1}$ (mass - ${ }_{\mathrm{A}^{-}}$; DTG - - -).

The samples morphology was characterized using SEM and the microphotographs are shown in Figure 5. It can be seen that pores within OP and AP are highly heterogeneous before adsorption of MB. However it is not the case after adsorption since a significant change is observed in the structure of the peels. They appear rougher with the formation of crater-like pores. Arami et al. (2005) explain this phenomenon by the package of pores involved by dye molecules.
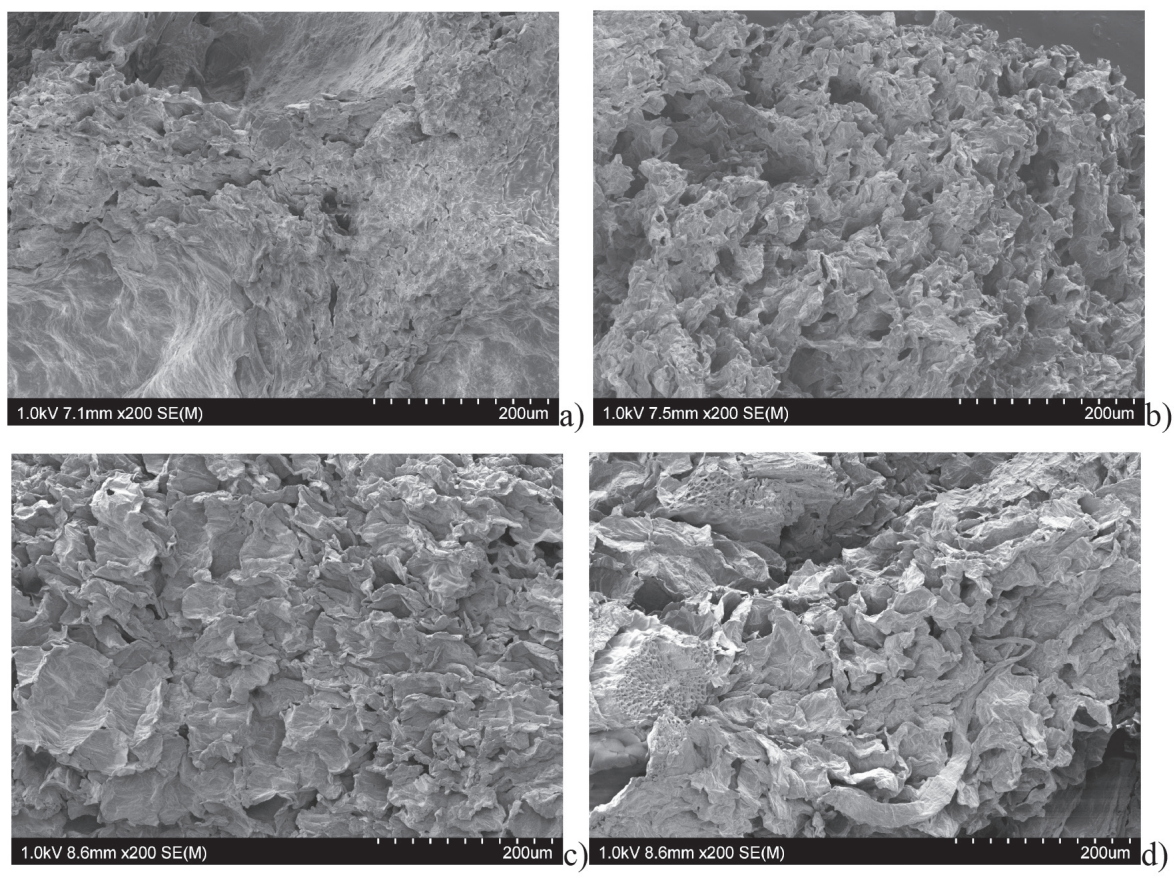

Figure 5. SEM analysis of : OP before (a) and after (b) MB sorption ; AP before (c) and after (d) MB sorption . 
Regarding size distribution of particles and porosity of substrates used, clear differences can be observed (Table 3). The total porosity of OP is about twice the AP one $(57,4 \%$ vs $29,7 \%)$ and the former substrate presents much larger pores hence a lower specific surface area than the latter. By considering that higher the area higher the available adsorption sites, we can assume that the adsorption onto OP should occur in a lesser extent than onto AP. Nevertheless other parameters have to be taken into account as extractives and lignin amounts as previously discussed.

Table 3. Porosity characterisation of biosorbents.

\begin{tabular}{|l|l|l|}
\hline \multicolumn{1}{|c|}{ Sample } & Almond peels & \multicolumn{1}{c|}{ Orange peels } \\
\hline Total cumulative volume $\left(\mathrm{mm}^{3} / \mathrm{g}\right)$ & 474,5534 & 732,4224 \\
\hline Total specific surface area $\left(\mathrm{m}^{2} / \mathrm{g}\right)$ & 35,233 & 10,528 \\
\hline Average pore diameter $(\mu \mathrm{m})$ & 3,96 & 11,64 \\
\hline Total porosity $(\%)$ & 29,7 & 57,4 \\
\hline
\end{tabular}

\section{Kinetics studies}

Figure 6 shows the uptake of dye from solution by orange and almond peels at $298 \mathrm{~K}$. It appears that the amount of MB adsorbed is concentration dependent and increases with initial concentration. The removal is rapid in the initial stages of contact time and gradually decreases with lapse of time until saturation. Further the amounts of dye adsorbed at equilibrium are in good agreement with those obtained in the adsorption of methylene blue by wheat shells (Bulut and Aydin 2006) or in the biosorption of methylene blue by Posidonia oceanica fibres (Ncibi et al. 2007).
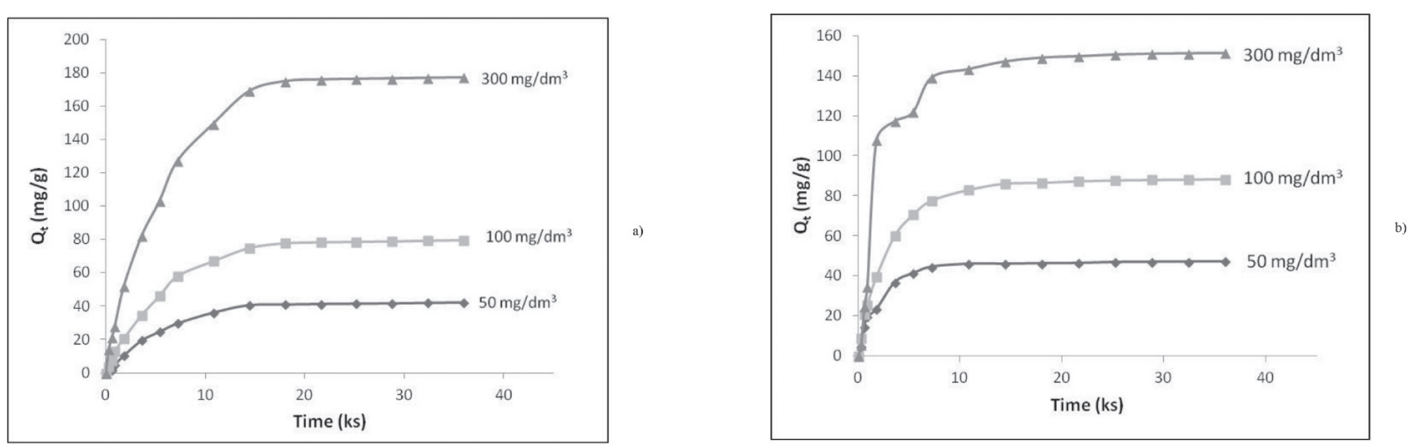

Figure 6. The effect of contacting time and initial solution concentrations on biosorption and removal efficiency of a) Orange peels and b) almond peels (dose of sorbent $=1 \mathrm{~g}, \mathrm{~V}=1 \mathrm{dm}^{3}, \mathrm{~T}=298 \mathrm{~K}$, Natural $\mathrm{pH}$ of solution i.e. mean values of $\mathrm{pH}$ comprised between 5,0 (beginning) and 4,2 (end of the experiment).

The applicability of first and pseudo-second order was tested for the adsorption of MB onto OP and AP. The best-fit model was selected based on the coefficients of determination, $\mathrm{R}^{2}$, values. 
For first order reaction, the model of Lagergren (1898) gives:

$$
\log \frac{\left(Q_{e}-Q_{t}\right)}{Q_{e}}=-\frac{K_{1} \times t}{2,3}
$$

While carrying $\log \left(\mathrm{Q}_{\mathrm{e}}-\mathrm{Q}_{\mathrm{t}}\right)$ versus $\mathrm{t}$, a straight line should be obtained whose slope gives $\mathrm{K}_{1}$, the rate constant of adsorption $\left(\mathrm{min}^{-1}\right)$.

For a pseudo second order reaction, the rate constant $\mathrm{K}^{2}$ is given by the equation (4) (Ho and McKay 1999, Ho and Mc Kay 2000):

$$
\frac{t}{Q_{t}}=\frac{1}{2 K_{2} Q_{e}^{2}}+\frac{t}{Q_{e}}
$$

By plotting $\mathrm{t} / \mathrm{Q}_{\mathrm{t}}$ versus $\mathrm{t}, \mathrm{K}_{2}$ (g.min $/ \mathrm{mg}$ ) can be derived.

With, in all the cases: $Q_{\mathrm{e}}$ : quantity adsorbed at equilibrium $(\mathrm{mg} / \mathrm{g}), \mathrm{Q}_{\mathrm{t}}$ : quantity adsorbed at time $\mathrm{t}(\mathrm{mg} / \mathrm{g})$, t: time of contact (min).

Even if we obtained straight lines with both models whatever the substrate and the initial concentration of dye (See for example Figure 7 related to adsorption kinetics on OP with concentrations 50, 100 and 300 $\mathrm{mg} / \mathrm{dm}^{3}$ ), the best suitable model to describe the adsorption of MB on both substrates is the pseudo second order. The coefficients of determination in this case are close to unity $\left(\mathrm{R}^{2} 0,98-0,99\right)$ as shown in Table 4 that summarizes all the results deduced from the two models (i.e. constants, $Q_{e}$ and $R^{2}$ ).
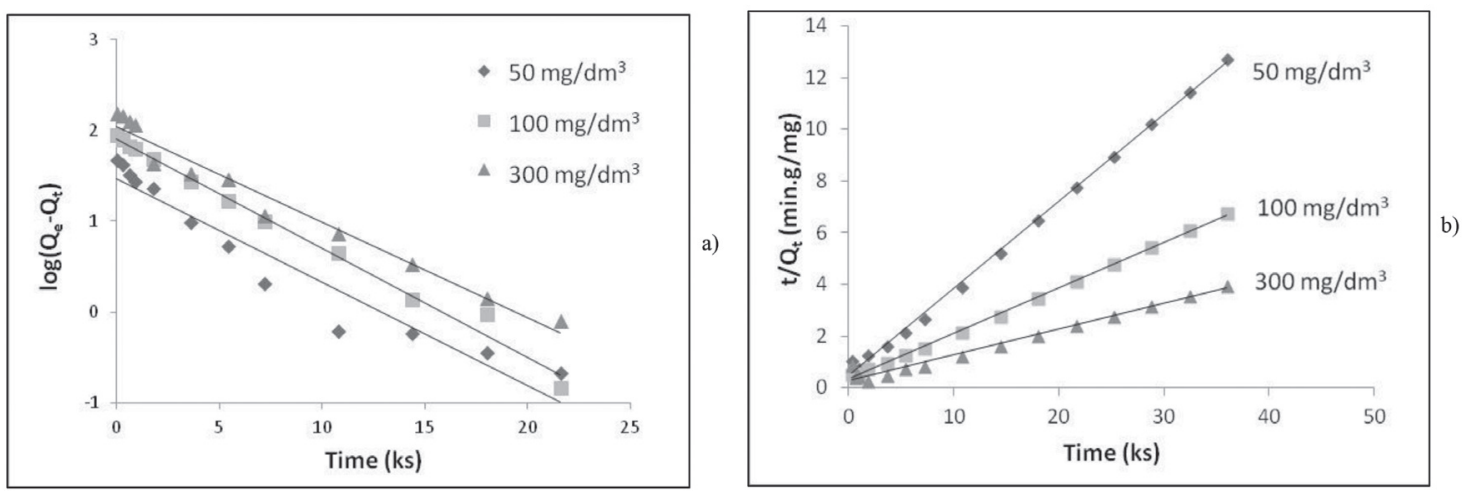

Figure 7. Determination of the rate constant for a) first order model and b) pseudo second. (substrate $=\mathrm{OP}$ ). 
Table 4. Kinetic constants and adsorption capacities calculated from different models.

\begin{tabular}{|l|c|c|c|c|c|c|}
\hline & \multicolumn{3}{|c|}{$\begin{array}{c}1^{\text {st }} \text { order } \\
\log \left(\mathrm{Q}_{\mathrm{e}}-\mathrm{Q}_{\mathrm{t}}\right)=\mathrm{f}(\mathrm{t})\end{array}$} & \multicolumn{3}{c|}{${\text { Pseudo } 2^{\text {nd }} \text { order }}_{\mathrm{t} / \mathrm{Q}_{\mathrm{t}}=\mathrm{f}(\mathrm{t})}$} \\
\hline Orange peels & $\begin{array}{c}\mathrm{K}_{1} \\
\left(\mathrm{~min}^{-1}\right)\end{array}$ & $\begin{array}{c}\mathrm{Q}_{\mathrm{e}} \text { calc } \\
(\mathrm{mg} / \mathrm{g})\end{array}$ & $\mathrm{R}^{2}$ & $\begin{array}{c}\mathrm{K}_{2} \\
(\mathrm{~g} \cdot \mathrm{min} / \mathrm{mg})\end{array}$ & $\begin{array}{c}\mathrm{Q}_{\mathrm{e}} \text { calc. } \\
(\mathrm{mg} / \mathrm{g})\end{array}$ & $\mathrm{R}^{2}$ \\
\hline $50 \mathrm{mg} / \mathrm{dm}^{3}$ & 0,01573 & 29,75 & 0,9355 & 0,000825 & 49,55 & 0,9983 \\
\hline $100 \mathrm{mg} / \mathrm{dm}^{3}$ & 0,01654 & 80,30 & 0,9905 & 0,000306 & 94,79 & 0,9988 \\
\hline $300 \mathrm{mg} / \mathrm{dm}^{3}$ & 0,01453 & 110,20 & 0,9704 & 0,000122 & 167,78 & 0,9796 \\
\hline
\end{tabular}

\begin{tabular}{|c|c|c|c|c|c|c|}
\hline & \multicolumn{3}{|c|}{$1^{\text {st }}$ order } & \multicolumn{3}{c|}{$\begin{array}{c}\text { Pseudo 2 } \\
\mathrm{Ld} / \mathrm{Q}_{\mathrm{t}}=\mathrm{f}(\mathrm{t})\end{array}$} \\
\hline $\begin{array}{c}\text { Almond } \\
\text { peels }\end{array}$ & $\begin{array}{c}\mathrm{K}_{1} \\
\left(\mathrm{~min}^{-1}\right)\end{array}$ & $\begin{array}{c}\mathrm{Q}_{\mathrm{e}} \text { calc. } \\
(\mathrm{mg} / \mathrm{g})\end{array}$ & $\mathrm{R}^{2}$ & $\begin{array}{c}\mathrm{K}_{2} \\
(\mathrm{~g} \cdot \mathrm{min} / \mathrm{mg})\end{array}$ & $\begin{array}{c}\mathrm{Q}_{\mathrm{e}} \text { calc. } \\
(\mathrm{mg} / \mathrm{g})\end{array}$ & $\mathrm{R}^{2}$ \\
\hline $50 \mathrm{mg} / \mathrm{dm}^{3}$ & 0,01438 & 49,51 & 0,9896 & 0,000118 & 56,95 & 0,9310 \\
\hline $100 \mathrm{mg} / \mathrm{dm}^{3}$ & 0,01493 & 99,01 & 0,9838 & 0,000109 & 95,88 & 0,9924 \\
\hline $300 \mathrm{mg} / \mathrm{dm}^{3}$ & 0,01605 & 227,86 & 0,9634 & 0,000061 & 207,04 & 0,9949 \\
\hline
\end{tabular}

These results are in good agreement with many researches carried out on MB adsorption on cellulosic substrates which is well described by a pseudo-second order model (Uddin et al. 2009, Ncibi et al. 2007, Bouhdadi et al. 2011).

\section{Determination of equilibrium model constants for MB-orange peels and MB-almond peels systems}

An adsorption isotherm is characterized by constants which give some indications about surface properties and affinity between adsorbate and adsorbent. In our case, the equilibrium data were fitted to the Langmuir and Freundlich isotherm models.

According to Langmuir's model, adsorption occurs through the formation of a monolayer of adsorbate and leads to the equation (5) (Kumar and Porkodi 2006):

$$
Q_{e}=Q_{m} \times \frac{K_{L} \times C_{e}}{1+K_{L} \times C_{e}}
$$

where $\mathrm{Q}_{\mathrm{m}}$ : maximum adsorption capacity $(\mathrm{mg} / \mathrm{g}), \mathrm{K}_{\mathrm{L}}$ : equilibrium constant, characteristic of the adsorbent $\left(\mathrm{dm}^{3} / \mathrm{mg}\right)$, depending on temperature and operating conditions and $\mathrm{C}_{\mathrm{e}}$ : concentration of the adsorbate at equilibrium $\left(\mathrm{mg} / \mathrm{dm}^{3}\right)$.

The Freundlich's model which application is limited to dilute media does not provide an upper limit to the adsorption and admits the existence of interactions between adsorbed molecules (Yang 1998). It is based on the empirical equation (6):

$$
Q_{e}=K_{F} \times\left(C_{e}\right)^{1 / n}
$$

with $\mathrm{C}_{\mathrm{e}}$ : concentration of adsorbate at equilibrium $\left(\mathrm{mg} / \mathrm{dm}^{3}\right), \mathrm{K}_{\mathrm{F}}$ : constant related to the adsorption capacity and $\mathrm{n}$ : heterogeneity factor. In most cases, the adsorption of dye does not follow a simple law 
Figure 8 shows the modelling of adsorption isotherms of MB using OP as an example according to Langmuir and Freundlich. The $\mathrm{Q}_{\mathrm{m}}, \mathrm{K}_{\mathrm{L}}, \mathrm{R}_{\mathrm{L}}{ }^{2}$ (coefficient of determination for Langmuir isotherm), $\mathrm{K}_{\mathrm{F}}, \mathrm{n}$, and $\mathrm{R}_{\mathrm{F}}^{2}$ (coefficient of determination for Freundlich isotherm) for both biosorbents are given in Table 5.

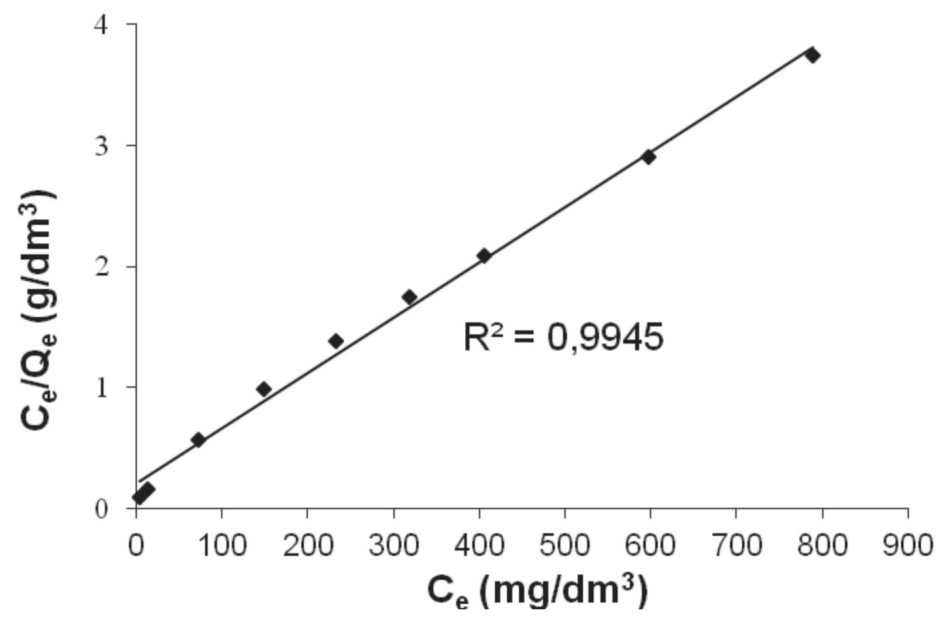

a)

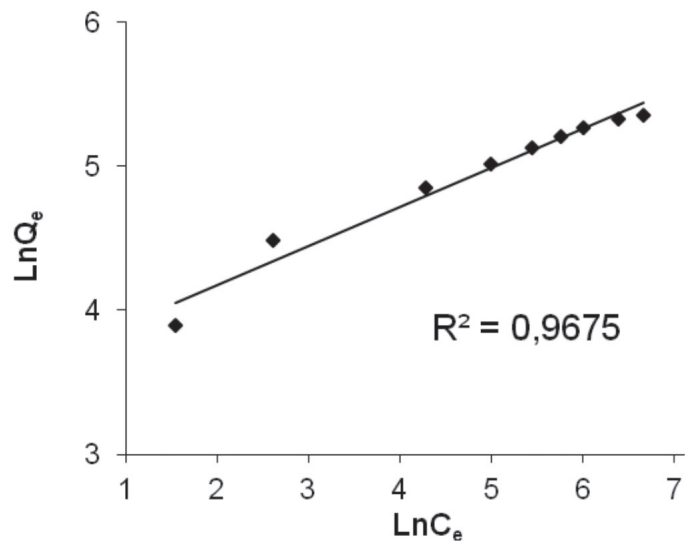

b)

Figure 8. MB adsorption according to Langmuir a) and Freundlich b) models on OP.

Table 5. Maximum amounts adsorbed and constants determined according to Langmuir and Freundlich adsorption models.

\begin{tabular}{|l|c|c|l|l|l|l|}
\hline \multirow{2}{*}{ Biosorbent } & \multicolumn{3}{|c|}{ Langmuir } & \multicolumn{3}{c|}{ Freundlich } \\
\cline { 2 - 7 } & $\mathrm{Q}_{\mathrm{m}}\left(\mathrm{mg} \cdot \mathrm{g}^{-1}\right)$ & $\mathrm{K}_{\mathrm{L}}\left(\mathrm{dm}^{3} \cdot \mathrm{mg}^{-1}\right)$ & $\mathrm{R}_{\mathrm{L}}{ }^{2}$ & $\mathrm{~K}_{\mathrm{F}}$ & $\mathrm{n}$ & $\mathrm{R}_{\mathrm{F}}{ }^{2}$ \\
\hline Orange peels & 218 & 0,022 & 0,9945 & 37,78 & 0,271 & 0,9675 \\
\hline Almond peels & 208 & 0,017 & 0,9927 & 28,31 & 0,312 & 0,9759 \\
\hline
\end{tabular}


The best-fit equilibrium model was chosen after the linear squared regression correlation coefficients $\mathrm{R}^{2}$. It appears that the adsorption phenomenon is better represented by Langmuir isotherm than Freundlich model because $\mathrm{R}_{\mathrm{L}}{ }^{2}(>0,992)$ are higher than $\mathrm{R}_{\mathrm{F}}{ }^{2}$ values $(<0,976)$. The applicability of the Langmuir isotherm suggests the monolayer coverage of the dye on the surface of both biosorbents. We have calculated the dimensionless constant called the equilibrium parameter $\mathrm{K}_{\mathrm{R}}$ which is defined by $\mathrm{K}_{\mathrm{R}}=1 /\left(1+\mathrm{K}_{\mathrm{L}} \mathrm{C}_{0}\right)$ where $\mathrm{K}_{\mathrm{L}}$ is the Langmuir constant $\left(\mathrm{dm}^{3} / \mathrm{mg}\right), \mathrm{C}_{0}$ is the initial dye concentration $\left(\mathrm{mg} / \mathrm{dm}^{3}\right)$. This parameter can give information about the characteristic of the isotherm. In our case, $\mathrm{K}_{\mathrm{R}}$ values between 0 and 1 at different concentrations indicate favourable adsorption of MB onto AP and OP as already observed for example in case of acidic dyes (Acid Violet 17) (Sivaraj et al. 2001) or (congo red and procion orange) (Namasivayam et al. 1996) on this latter biosorbent.

The adsorption capacities found ( $218 \mathrm{mg} / \mathrm{g}$ for OP, $208 \mathrm{mg} / \mathrm{g}$ for AP) are higher than some sorbent materials reported in the literature such as: tea waste (Uddin et al. 2009), chaff (Han et al. 2006) broad bean peels (Hameed and Khaiary 2008), but lower than those obtained using other adsorbents such as activated carbons (Kannan and Sundaram 2001, El Qada et al. 2008, Stavropoulos and Zabaniotou 2005) mainly because their specific areas are significantly different.

Reminding the porosity characterization and particularly the estimated specific area of our substrates OP and AP, we expected that adsorption took place in a greater extent on AP. Nevertheless, according to our results, OP appears as a quite better biosorbent than AP. Taking into account that both substrates have the same holocellulose content, the difference in adsorption capacity could be probably attributed to the total porosity of sorbents and their pores size rather than their specific area. OP is more porous and presents larger pores than AP hence a higher amount of dye removed.

\section{Thermodynamic parameters of biosorption}

To estimate the effect of temperature on the adsorption of $\mathrm{MB}$ on orange and almond peels, thermodynamic parameters were determined from the apparent equilibrium constant $\mathrm{Kc}$ of biosorption which is defined as:

$$
\mathrm{Kc}=\left(\mathrm{C}_{0}-\mathrm{C}_{\mathrm{e}}\right) / \mathrm{C}_{\mathrm{e}}
$$

where $\mathrm{C}_{0}=$ initial concentration $\left(\mathrm{mg} / \mathrm{dm}^{3}\right)$ and $\mathrm{C}_{\mathrm{e}}=$ equilibrium concentration $\left(\mathrm{mg} / \mathrm{dm}^{3}\right) . \mathrm{Kc}$ is linked to $\Delta G^{\circ}$ hence to $\Delta H^{\circ}$ and $\Delta S^{\circ}$ as follows in equation (8):

$$
\Delta G^{\circ}=\Delta H^{\circ}-T \Delta S^{\circ}=-R \cdot T \cdot \ln (\mathrm{Kc})
$$

and consequently

$$
\ln (K \mathrm{c})=-\Delta H^{\circ} / R T+\Delta S^{\circ} / R
$$

with $\Delta G^{\circ}$, the standard Gibbs free energy change $(\mathrm{J} / \mathrm{mol}), \Delta H^{\circ}$, the standard enthalpy change $(\mathrm{J} / \mathrm{mol}), \Delta S^{\circ}$, the entropy change $(\mathrm{J} / \mathrm{mol} . \mathrm{K}), \mathrm{R}$ the universal gas constant $(8,314 \mathrm{~J} / \mathrm{mol} . \mathrm{K})$ and $\mathrm{T}$ the absolute temperature $(\mathrm{K})$.

The plot of $\ln (\mathrm{Kc})$ versus $1 / \mathrm{T}$ leads to values of $\Delta H^{\circ}$ and $\Delta S^{\circ}$ and the results are given in Table 6 . 
Table 6. Thermodynamics associated with adsorption onto orange and almond peels.

\begin{tabular}{|c|c|c|c|c|c|c|}
\hline \multirow[t]{2}{*}{ Substrate } & \multirow{2}{*}{$\begin{array}{c}\Delta H^{\circ} \\
(\mathrm{kJ} / \mathrm{mol})\end{array}$} & \multirow{2}{*}{$\begin{array}{c}\Delta S^{\circ} \\
(\mathrm{J} / \mathrm{mol} / \mathrm{K})\end{array}$} & \multicolumn{3}{|c|}{$\Delta G^{\circ}(\mathrm{J} / \mathrm{mol})$ at } & \multirow[t]{2}{*}{$\mathrm{R}^{2}$} \\
\hline & & & $298 \mathrm{~K}$ & $308 \mathrm{~K}$ & $318 \mathrm{~K}$ & \\
\hline Orange peels & 14,8164 & 75,230 & $-7658,28$ & $-8242,61$ & $-9162,89$ & 0,9836 \\
\hline Almond peels & 7,048704 & 47,343 & $-7077,11$ & $-7497,74$ & $-8023,97$ & 0,9959 \\
\hline
\end{tabular}

In both cases, the negative values of Gibbs free energy change indicate that the adsorption process is spontaneous. Besides the positive values of $\Delta H^{\circ}$ show that it is also endothermic i.e. the adsorption increases as the temperature increases. The positive values of $\Delta S^{\circ}$ suggest the increased randomness at the solid/solution interface during the adsorption of dye on the sorbent.

\section{CONCLUSIONS}

The present study shows that orange and almond peels can be efficiently used as biosorbents for the removal of methylene blue from aqueous solutions. The quantity of dye adsorbed depends on the initial dye concentration, the contacting time and the temperature and increases with an increase of these three parameters. The rate of adsorption conforms to pseudo-second-order kinetics with a good correlation and the equilibrium modelling by Langmuir isotherm equation indicates a monolayer adsorption capacity of MB on OP and $\mathrm{AP}$ (monolayer adsorption capacity quite similar on both biosorbents i.e. $218,82 \mathrm{mg} / \mathrm{g}$ for OP and $208,82 \mathrm{mg} / \mathrm{g}$ for AP).The thermodynamic parameters determined at different temperatures show that MB adsorption is spontaneous and endothermic. Orange and almond peels, low cost and easily available material, can be interesting alternative for more expensive adsorbents used for dye removal in waste treatment processes.

\section{ACKNOWLEDGMENTS}

The authors express their sincere gratitude to Dr Yves Pillet for analytical support of this study. 


\section{REFERENCES}

Aksu, Z. 2005. Application of biosorption for the removal of organic pollutants: a review. Process Biochem 40: 997-1026.

Arami, M.; Limaee, N.Y.; Mahmoodi, N.M.; Tabrizi, N.S. 2005. Removal of dyes from colored textile wastewater by orange peel adsorbent: equilibrium and kinetic studies. J Colloid Interface Sci 288: 371-376.

Benturki, O.S.; Donnot, A.; Molina, S.; Merlin, A.; Addoun, F. 2008. Synthesis and characterization of activated carbons obtained from jujube shells "Nebka". J Soc Alger Chim 18: 7-23.

Bilbao, R.; Mastral, J. F.; Aldea, M. E.; Ceamanos, J. 1997. The influence of the percentage of oxygen in the atmosphere on the thermal decomposition of lignocellulosic materials. J Anal Appl Pyrolysis 42: 189-202.

Bouhdadi, R.; EI Moussaouiti, M.; George, B.; Molina, S.; Merlin, A. 2011. Acylation de la cellulose par le chlorhydrate de chlorure de 3-pyridinoyl : application dans l'adsorption du plomb $\mathrm{Pb}^{2+}$. CRChimie 14:539-547.

Bulut, Y.; Aydin, H. 2006. A kinetics and thermodynamics study of methylene blue adsorption on wheat shells. Desalination 194: 259-267.

Chen, H.; Zhao, W.; Liu, N. 2011. Thermal analysis and decomposition kinetics of Chinese forest peat under nitrogen and air atmospheres. Energy Fuels 25: 797-803.

Daneshvar, N.; Aber, S.; Khani, A.; Khataee, A.R. 2007. Study of imidaclopride removal from aqueous solution by adsorption onto granular activated carbon using an on-line spectrophotometric analysis system. J Hazard Mater 144: 47-51.

El Qada, E.N.; Allen, S.J.; Walker, G.M. 2008. Adsorption of basic dyes from aqueous solution onto activated carbons. Chem Eng $J$ 135: 174-184.

Font, R.; Marcilla, A.; Verdú, E.; Devesa, J. 1991. Thermogravimetric kinetic study of the pyrolysis of almond shells and almond shells impregnated with $\mathrm{CoCl}_{2} . J$ Anal Appl Pyrolysis 21: 249-264.

Ghanadzadeh, A.; Zeini, A.; Kashef, A.; Moghadam, M. 2008. Concentration effect on the absorption spectra of oxazine1 and methylene blue in aqueous and alcoholic solutions. J Mol Liq 138:100-106.

Hameed, B.H.; l-Khaiary, M.I. 2008. Sorption kinetics and isotherm studies of a cationic dye using agricultural waste: broad bean peels. J Hazard Mater 154: 639-648.

Hameed, B.H. 2009. Spent tea leaves: A new non-conventional and low-cost adsorbent for removal of basic dye from aqueous solutions. J Hazard Mater 161: 753-759.

Han, R.; Wang, Y.; Han, P.; Shi, J.; Yang, J.; Lu, Y. 2006. Removal of methylene blue from aqueous solution by chaff in batch mode. J Hazard Mater B137: 550-557.

Han, R.; Zou, W.; Yu, W.; Cheng, S.; Wang, Y.; Shi, J. 2007. Biosorption of methylene blue from aqueous solution by fallen phoenix tree's leaves. J Hazard Mater 141: 156-162.

Ho, Y.S.; McKay, G. 1999. Pseudo-second order model for sorption processes. Process Biochem 34: 451-465. 
Ho, Y.S.; McKay, G. 2000.The kinetics of sorption of divalent metal ions onto sphagnum moss peat. Water Res 34: 735-742.

Janoš, P.; Buchtová, H.; Rýznarová, M. 2003. Sorption of dyes from aqueous solutions onto fly ash. Water Res 37: 4938-4944.

Kannan, N.; Sundaram, M.M. 2001. Kinetics and mechanism of removal of methylene blue by adsorption on various carbons- a comparative study. Dyes Pigments 51: 25-40.

Kumar, K.V.; Porkodi, K. 2006. Letter to the Editor: Relation between some two- and three-parameter isotherm models for the sorption of methylene blue onto lemon peel. J Hazard Mater 138: 633-635.

Lagergren, S. 1898. About the theory of so-called adsorption of soluble substances. K Svenska Vetenskapsakad Handl 24: 1-39.

Li, X.; Tang, Y.; Cao, X.; Lu, D.; Luo, F.; Shao, W. 2008a. Preparation and evaluation of orange peel cellulose adsorbents for effective removal of cadmium, zinc, cobalt and nickel. Colloid Surface Physicochem Eng Aspect 317: 512-521.

Li, Y.; Zhang, J.; Zhang, C.; Wang, L.; Zhang, B. 2008b. Biosorption of methylene blue from aqueous solution by softstem bulrush (Scirpus tabernaemontani Gmel.). J Chem Technol Biotechnol 83: 1639-1647.

Lü, L.; Chen, L.; Shao, W.; Luo, F. 2010. Equilibrium and kinetic modeling of Pb(II) biosorption by a chemically modified orange peel containing Cyanex 272. J Chem Eng Data 55: 4147-4153.

Martin, B.B.;Martin D.F.; Perez-Cruet M.J. 1987. Effect of selected dyes on the growth of the filamentous blue-green alga, Lyngbya Majescula. J Aquat Plant Manage 25:40-43.

Nacèra, Y.; Aicha, B. 2006. Equilibrium and kinetic modelling of methylene blue biosorption by pretreated dead streptomyces rimosus: Effect of temperature. Chem Eng J 119: 121-125.

Namasivayam, C.; Muniasamy, N.; Gayatri, K.; Rani, M.; Ranganathan, K. 1996. Removal of dyes from aqueous solutions by cellulosic waste orange peel. Bioresour Technol 57: 37-43.

Ncibi, M.C.; Mahjoub, B.; Seffen, M. 2007. Kinetic and equilibrium studies of methylene blue biosorption by Posidonia oceanica (L.) fibres. J Hazard Mater B139: 280-285.

Nguila Inari, G.; Pétrissans, M.; Gérardin, P. 2007. Chemical reactivity of heat-treated wood. Wood Sci Technol 41: 157-168.

Orfão, J.J.M.; Antunes, F.J.A.; Figueiredo, J.L. 1999. Pyrolysis kinetics of lignocellulosic materials - Three independent reactions model. Fuel 78: 349-358.

Otero, M.; Rozada, F.; Calvo, L.F.; García, A.I.; Morán, A. 2003. Kinetic and equilibrium modelling of the methylene blue removal from solution by adsorbent materials produced from sewage sludges. Biochem Eng J 15: 59-68.

Patil, K.; Pawar, R.; Talap, P. 2000. Self-aggregation of Methylene Blue in aqueous medium and aqueous solutions of Bu4NBr and urea. Phys Chem Chem Phys 2:4313-4317.

Robinson, T.; McMullan, G.; Marchant, R.; Nigam, P. 2001. Remediation of dyes in textile effluent: a critical review on current treatment technologies with a proposed alternative. Bioresour Technol 77: 247-255. 
Sivaraj, R.; Namasivayam, C.; Kadirvelu, K. 2001. Orange peel as an adsorbent in the removal of Acid violet 17 (acid dye) from aqueous solutions. Waste Management 21:105-110.

Soares, S.; Camino, G.; Levchik, S. 1995. Comparative study of the thermal decomposition of pure cellulose and pulp paper. Polym Degrad Stab 49: 275-283.

Stavropoulos, G.G.; Zabaniotou, A.A. 2005. Production and characterization of activated carbons from olive-seed waste residue. Microporous Mesoporous Mater 82:79-85.

Suárez-García, F.; Martínez-Alonso, A.; Tascón, J.M.D. 2002. A comparative study of the thermal decomposition of apple pulp in the absence and presence of phosphoric acid. Polym Degrad Stab 75: 375-383.

Tafulo, P.A.R.; Queirós, R.B.; González-Aguilar, G. 2009. On the "concentration-driven" methylene blue dimerization. Spectrochimica Acta part A 73:295-300.

Tsai, J.H.; Chiang, H.M.; Huang, G.Y.; Chiang, H.L. 2008. Adsorption characteristics of acetone, chloroform and acetonitrile on sludge-derived adsorbent, commercial granular activated carbon and activated carbon fibers. J Hazard Mater 154: 1183-1191.

Uddin, Md.T.; Islam, Md.A.; Mahmud, S.; Rukanuzzaman, Md. 2009. Adsorptive removal of methylene blue by tea waste. J Hazard Mater 164: 53-60.

Wang, S.; Zhu, Z.H.; Coomes, A.; Haghseresht, F.; Lu, G.Q. 2005. The physical and surface chemical characteristics of activated carbons and the sorption of methylene blue from wastewater. J Colloid Interf Sci 284: 440-446.

Wongsiriamnuay, T.; Tippayawong, N. 2010. Thermogravimetric analysis of giant sensitive plants under air atmosphere. Bioresour Technol 101: 9314-9320.

Yang, C.H. 1998. Statistical Mechanical on the Freundlich Isotherm Equation. J. Colloid Interface Sci. 208: 379-387.

Yang, H.; Yan, R.; Chen, H.; Lee, D.H.; Zheng, C. 2007. Characteristics of hemicellulose, cellulose and lignin pyrolysis. Fuel 86:1781-1788.

Zapata, B.; Balmaseda, J.; Fregoso-Israel, E.; Torres-Garcia, E. 2009. Thermo-kinetics study of orange peel in air. $J$ Therm Anal Calorim 98: 309-315. 